\title{
Addressing Academic and Behavior Literacy across the Ages through Integrated Evidence-Based Strategies
}

\author{
Kristine Jolivette • Carol A. Donovan • Sara Sanders
}

Published online: 10 February 2020

(C) Association for Behavior Analysis International 2020

Children and youth with emotional and behavioral disorders (E/BD) may present simultaneous academic, behavioral, and socioemotional excesses and/or deficits during instruction. In addition, there are many other school-age children and youth who are not eligible for special education services but also present such challenges. No matter one's eligibility, educators need methods to address these excesses and/or deficits in an effective and proactive manner while continuing to provide academic instruction.

This special issue of Education and Treatment of Children and Youth focuses on two issues found across educational settings and ages, including preschool, elementary, and middle schools as well as general education inclusive classrooms, and resource and selfcontained special education classrooms with this population.

The first focus is on academic literacy instructional methods that can be considered best-practices that can support academic instruction across content areas (reading, writing, math). The term "literacy" is used in many contexts and in many different ways. Literacy educators consider literacy to include reading and writing as components of the language arts within the context of learning about the world (e.g., Heath 1984; Street 1984).

K. Jolivette $(\bowtie) \cdot$ C. A. Donovan · S. Sanders University of Alabama, Tuscaloosa, AL, USA e-mail: jolivette@ua.edu

\section{S. Sanders}

e-mail: sara.sanders@ua.edu
Journal titles and professional organizations for reading researchers began using the term "literacy" rather than "reading." For example, the International Reading Association changed its organization name to International Literacy Association in 2015 to acknowledge the complex array of social, cultural, and cognitive constructs at play in being literate in the twenty-first century. "Literacy," however, is also considered more broadly in education to mean having language, knowledge, and skills in a given area (Moschkovich 2015). In this special issue, we use the term in the broader sense to mean developing the language, knowledge, and skills to gain competence in a content area. Thus, academic and behavioral literacy in this special issue refers to content area learning in math (math literacy) as well as reading and writing (literacy), and ability to self-regulate behavior (behavior literacy). Some of the manuscripts address literacy through the implementation of the self-regulated strategy development (SRSD) framework. The SRSD framework is an evidence-based framework used to teach writing skills (Losinski et al. 2014) and is a promising framework for teaching reading comprehension (Sanders et al. 2019). SRSD also has been extended beyond writing and reading to the area of math (e.g., Losinski et al. 2018).

The second focus is on simultaneously meeting the behavioral and socioemotional needs of children and youth by embedding self-regulation strategies within academic instruction. SRSD combines the direct instruction of an academic skill with scaffolded support in the use of self-regulation skills (Harris and Graham 1999). Broadly defined, self-regulation is the ability to 
develop a plan for a task, self-monitor, and self-evaluate progress to ultimately complete a task (Noonan and Gaumer Erickson 2018; Zimmerman 2008). Selfregulation skills include goal setting, self-reinforcement, self-monitoring, and self-talk (also called self-statements or self-instructions; Harris and Graham 1999). Children and youth who can effectively self-regulate their behavior are able to monitor progress towards goals and alter their behavior in order to meet such goals, a skill that is valuable when working to improve academic literacy (Noonan and Gaumer Erickson 2018). Although some children and youth may be able to utilize self-regulation skills with little to no direct instruction, others may need more intensive instruction on how to use self-regulation skills to reach their academic goals (Harris et al. 2004). Researchers have established academic benefits attributed to the use of self-regulation skills of children and youth, in particular among secondary students (e.g., Nota et al. 2004; Zimmerman and Kitsantas 2014). Readers may find the Insight Center in Boston helpful as it has a large collection of self-regulation resources for both teachers and researchers (Self-Regulation n.d.). Although not specifically focused on self-regulation, some other reading programs (e.g., Corrective Reading Decoding) do contain elements of self-regulation to blend both academic and behavioral instruction.

In addition, this special issue highlights the importance and feasibility of prevention to minimize entrenched academic error patterns (e.g., not being able to comprehend what was read; not being fluent in basic math computations; not being able to write coherent text) and histories of challenging behaviors during instruction (e.g., noncompliance, disruption). For example, there is much evidence to support the importance of early intervention and high-quality early education for preventing educational difficulties. Providing high-quality home and preschool experiences positively affect language and literacy development (e.g., Dickinson and Porche 2011) including reducing gaps associated with living in poverty (e.g., Pianta et al. 2009), which in turn can affect schoolage reading achievement (e.g., Smart et al. 2005). Inclusive preschool experiences for children with and without disabilities provide opportunities for strengthening language, literacy, and socioemotional skills needed for later school success (e.g., Hebbeler and Spiker 2016). Emphasizing early education is critical. Likewise, continued support is vital for students to become proficient readers and writers as they progress throughout school due to the established link between levels of literacy and improved postsecondary job opportunities (Wood 2010). Delivering academic content integrated with self-regulation skills allows teachers to maximize the opportunities for student growth during school years. Combining best practices for academic and behavioral/socioemotional learning in addition to preventative measures sets the stage for maximal school-based outcomes and future success postschool.

This special issue includes articles discussing issues that are part of our foci. Kerch, Donovan, Ernst, Strichik, and Winchester's study highlights receptive vocabulary development and social competencies of young children with and without disabilities in a state prekindergarten program. They found that those young children without disabilities and higher protective factors displayed fewer externalizing behaviors yet had higher language development; however, young children with disabilities continued to struggle with self-regulation skills. Sanders, Losinski, Ennis, Lane, White, and Teagarden studied the use of the SRSD reading strategy TWA with fourth, fifth, and sixth graders with — and at-risk for-E/BD. Although the treatment group did not show significant improvement in reading comprehension over the control group, student response to the strategy was positive and anecdotal improvements in behaviors were noted. McKeown, FitzPatrick, Ennis, and Potter's study investigated the effects of asynchronous audio feedback, provided by inclusive special education teachers who used the SRSD instructional approach, on the persuasive elements, holistic quality, and substantive revision skills of eight fifith grade students with comorbid writing and behavioral challenges. They found that the use of technology-based feedback improved the writing skills anddecreased the behavioral concerns presented during writing tasks of the students. Foorman, Lee, and Smith's manuscript highlights evidence-based and best practices for reading intervention as well as reading resources for use by educators working with children in kindergarten through third grade within the context of multitiered systems of support. These resources include free access materials offered through many federal and state venues as well as research articles. Sanders' study investigated the effects of the SRSD strategy, TRAP, on the reading comprehension skills of four students with behavior challenges in grades fifth and sixth using a multiplebaseline across students design. They found a functional relation with improved student reading comprehension scores while maintaining high levels of fidelity and positive social validity scores. FitzPatrick and McKeown's 
study investigated the effects of writing SRSD, following practice-based professional development, on the fidelity of implementation and effects on holistic quality, analytic quality, and use of academic vocabulary and length with middle-school students with learning disabilities or $\mathrm{E} / \mathrm{BD}$. They found that the teacher could implement the intervention with fidelity and students improved in their writing but struggled with the self-regulation aspects of positive self-statements. Ennis and Losinski's article highlights the extension of the SRSD framework to math. They highlight the research in this area and detail several new mathematical SRSD strategies. Benner, Jolivette, and Baylin studied the collective and differentiated effects of a remedial reading intervention on the reading and social adjustment problems of elementary and middle-school students with learning disabilities and E/BD. They found statistically significant improvements in the basic reading scores of both populations and statistically significant reductions in internalizing and inattention social adjustment behavior. In addition, they found that students with $\mathrm{E} / \mathrm{BD}$ made more improvements than the students with learning disabilities.

As we continue to provide effective academic and behavioral/socioemotional instruction across ages and settings for children and youth with $\mathrm{E} / \mathrm{BD}$, it will be imperative to study the effects of the interventions applied. This special issue focuses on academic instructional methods with embedded self-regulated strategies to best target the comorbid needs of children and youth with $\mathrm{E} / \mathrm{BD}$. We encourage others to continue investigating these integrated methods and strategies for this population across ages and settings so that all children and youth are afforded the same educational opportunities.

\section{References}

Dickinson, D. K., \& Porche, M. (2011). Relationship between language experiences in preschool classrooms and children's kindergarten and fourth grade language and reading abilities. Child Development, 82, 870-886.

Harris, K. R., \& Graham, S. (1999). Programmatic intervention research: Illustrations from the evolution of self-regulated strategy development. Learning Disability Quarterly, 22, 251-262.

Harris, K. R., Reid, R. R., \& Graham, S. (2004). Self-regulation among students with $\mathrm{LD}$ and ADHD. Learning about Learning Disabilities, 3, 167-195.

Heath, S. B. (1984). Ways with words: Language, life and work in communities and classrooms. Cambridge: Cambridge University Press.
Hebbeler, K., Spiker, D. (2016). Supporting young children with disabilities. The Future of Children, 26, 185-205. Retrieved from http://www.jstor.org/stable/43940587.

Losinski, M., Cuenca-Carlino, Y., Zablocki, M., \& Teagarden, J. (2014). Examining the efficacy of self-regulated strategy development for students with emotional/behavioral disorders: A meta-analysis. Behavioral Disorders, 40, 52-67.

Losinski, M., Ennis, R. P., Sanders, S., \& Wiseman, N. (2018). An investigation of self-regulated strategy development to teach addition and subtraction of fractions to students with or atrisk for disabilities. Exceptional Children, 85, 291-308.

Moschkovich, J. (2015). A sociocultural approach to academic literacy in mathematics for adolescent English learners: Integrating mathematical proficiency, practices, and discourse. In D. Molle, E. Sato, T. Boals, \& C. A. Hedgspeth (Eds.), Social contexts of literacy development in adolescents (pp. ). New York, NY: Routledge.

Noonan, P. M., \& Gaumer Erickson, A. S. (2018). The skills that matter: Teaching interpersonal and intrapersonal competencies in any classroom. Thousand Oaks: Corwin.

Nota, L., Soresi, S., \& Zimmerman, B. J. (2004). Self-regulation and academic achievement: Why do implicit beliefs, goals, and effort matter? Learning \& Individual Differences, 25, 67-72.

Pianta, R. C., Barnett, S. W., Burchinal, M., \& Thornburg, K. R. (2009). The effects of preschool education: What we know, how public policy is or is not aligned with the evidence base, and what we need to know. Psychological Science in the Public Interest, 10(2), 49-88. https://doi.org/10.1177 /1529100610381908.

Sanders, S., Losinski, M., Ennis, R. P., White, W., Teagarden, J., \& Lane, J. (2019). A meta-analysis of self-regulated strategy development (SRSD) reading interventions to improve reading comprehension of students with disabilities. Reading \& Writing Quarterly, 4, 339-353 https://doi.org/10.1080 /10573569.2018.1545616.

Self-Regulation. (n.d.). Insight Center: By Boston After School \& Beyond. Retrieved from http://insight.bostonbeyond.org/actskills/thrive/self-regulation/. Accessd 3 May 2019.

Smart, D., Prior, M., Sansor, A., \& Oberkind, F. (2005). Children with reading difficulties: A six year follow-up from early primary to secondary school. Australia Journal of Learning Difficulties, 10, 63-75.

Street, B. (1984). Literacy in theory and practice. Cambridge: Cambridge University Press.

Wood, W. C. (2010). Literacy and the entry-level workforce: The role of literacy and policy in labor market success. Washington, DC: Employment Policies Institute.

Zimmerman, B. J. (2008). Investigating self-regulation and motivation: Historical background, methodological developments, and future projects. American Educational Research Journal, 45, 166-183.

Zimmerman, B. J., \& Kitsantas, A. (2014). Comparing students' self-discipline and self-regulation measures and their prediction of academic achievement. Contemporary Educational Psychology, 39, 145-155.

Publisher's Note Springer Nature remains neutral with regard to jurisdictional claims in published maps and institutional affiliations. 